\title{
Relação do tempo de treinamento e autoeficácia com o autoconceito e a qualidade de vida em jovens escolares de Basquetebol
}

\author{
Relationship of training time and self-efficacy with self-concept and quality of life in young \\ basketball students
}

Relación del tiempo de entrenamiento y la autoeficacia con el autoconcepto y la calidad de vida en jóvenes estudiantes de baloncesto

Recebido: 25/01/2022 | Revisado: 29/01/2022 | Aceito: 02/02/2022 | Publicado: 04/02/2022

\author{
Adair José Pereira da Rocha \\ ORCID: https://orcid.org/0000-0002-3308-121X \\ Universidade Federal do Paraná, Brasil \\ E-mail adairbasquetecuritiba@gmail.com \\ Renato Rodrigues Biscaia \\ ORCID: https://orcid.org/0000-0002-3824-8584 \\ Universidade Federal do Paraná, Brasil \\ E-mail: renato.rodriguesbiscaia@hotmail.com \\ Fabio Ricardo Hilgenberg Gomes \\ ORCID: https://orcid.org/0000-0002-0809-2611 \\ Universidade Federal do Paraná, Brasil \\ E-mail: frblan@msn.com \\ Gislaine Cristina Vagetti \\ ORCID: https://orcid.org/0000-0003-0704-1297 \\ Universidade Estadual do Paraná, Brasil \\ E-mail: gislainevagetti@hotmail.com \\ Valdomiro de Oliveira \\ ORCID: https://orcid.org/0000-0002-8709-8471 \\ Universidade Federal do Paraná, Brasil \\ E-mail: oliveirav457@gmail.com
}

\begin{abstract}
Resumo
O estudo objetivou analisar a relação do tempo de treinamento e da autoeficácia com o autoconceito e a qualidade de vida em jovens escolares de Basquetebol. Foram avaliadas as respostas de 197 alunos/atletas de 12 a 17 anos do sexo feminino e masculino de ambientes onde o basquetebol é ofertado na região de Curitiba, Paraná, tais como escolas, clubes e centros de ensino da prefeitura. Constatou-se escores altos para o autoconceito nos domínios de autonomia, financeiro e escola, como também na qualidade de vida geral, com relação ao tempo de treinamento. Conclui-se que existem diferenças do ponto de vista quantitativo, sugerindo que se possa contribuir para a percepção positiva da qualidade de vida, no autoconceito e na autoeficácia, sendo estes associados ao tempo de treinamento.
\end{abstract}

Palavras-chave: Qualidade de vida; Autoconceito; Basquetebol; Autoeficácia; Estudantes.

\begin{abstract}
The study aimed to analyze the relationship between training time and self-efficacy with self-concept and quality of life in young basketball students. The responses of 197 female and male students/athletes aged between 12 and 17 from environments where basketball is offered in the region of Curitiba, Paraná, such as schools, clubs and teaching centers of the city hall, were evaluated. High scores were found for self-concept in the domains of autonomy, finances and school, as well as in general quality of life, in relation to training time. It is concluded that there are differences from a quantitative point of view, suggesting that one can contribute to a positive perception of quality of life, selfconcept and self-efficacy, which are associated with training time.
\end{abstract}

Keywords: Quality of life; Self-concept; Basketball; Self-efficacy; Students.

\section{Resumen}

El estudio tuvo como objetivo analizar la relación entre el tiempo de entrenamiento y la autoeficacia con el autoconcepto y la calidad de vida en estudiantes de baloncesto. 19 género masculino de las regiones19 como respuestas de 12 a estudiantes/atletas varones 12 a varones de ambientes donde se imparte educación masculina en los centros municipales de Curitiba, Paraná. Se encontraron puntajes altos para el autoconcepto en los dominios de autonomía, finanzas y escuela, así como en calidad de vida general, en cuanto al tiempo de formación. Se concluye 
que existen diferencias desde el punto de vista laboral, sugiriendo que se puede contribuir a una percepción positiva de la calidad de vida, el autoconcepto y la autoeficacia, que se asocian al tiempo de formación.

Palabras clave: Calidad de vida; Autoconcepto; Baloncesto; Autoeficacia; Estudiantes.

\section{Introdução}

O basquetebol é uma modalidade olímpica que demanda aos jovens escolares aperfeiçoarem a inteligência, prepararse emocionalmente, trabalhar o lado psicológico, físico, técnico, tático, ter conhecimento dos valores do esporte, tais como o espírito de equipe, o respeito pelas pessoas, o fair play e a superação, os quais estão inseridos em um ambiente de competição não apenas em jogos federativos, mas também nos jogos escolares.

Os maiores objetivos do jogo, são ter uma defesa eficaz que provoque o erro do adversário e um ataque eficiente na execução das cestas, para que assim possa vencer a partida, que é disputada em 4 tempos de 10 minutos em competições na escola até as consideradas profissionais, pois seguem as regras da Federação Internacional de Basketball (FIBA, 2020; Oliveira et al., 2020).

Uma vertente importante de estudos relacionados ao basquetebol vem sendo desenvolvida acerca do lado psicopedagógico desta modalidade que se inicia nas aulas de educação física agregada a pedagogia do esporte, que contempla as percepções do comportamento do indivíduo no ambiente esportivo, podendo esse ambiente ser favorável ou não. Além disso, o basquete pode influenciar o desenvolvimento do adolescente, tanto na parte psicológica quanto na parte biológica, as quais podem estar atreladas ao início de sua formação e ao final de sua trajetória educacional/esportiva.

Estudos sugerem que exista um equilíbrio psicológico, principalmente na iniciação do basquete, onde há orientações com esquemas organizados e planejados com base na pedagogia do esporte, oportunizando o aprendizado adequado à idade e ao nível individual dos alunos/atletas tornaram-se fundamentais para o bom desenvolvimento (Rose, 2002; Galatti, 2006; Oliveira et al., 2012; Oliveira et al., 2020).

A Pedagogia do Esporte dentro da escola deve seguir uma periodização para os esportes coletivos com uma linha de raciocínio gradual para as passagens dos níveis, partindo de uma inicial, mais simples, até um treino complexo com aspectos técnicos e táticos que exigem de seus praticantes preparação física, coordenação motora e estimulação cognitiva, de modo a compreender e absorver problemas que o jogo de basquete possibilita, como a dinâmica, a habilidade e a inteligência que se pede no momento do jogo (Oliveira et al., 2020).

O basquetebol é praticado por diversas faixas etárias, no entanto mostra-se como uma ferramenta psicopedagógica interessante para jovens atletas em fase escolar, entre a pré-adolescência e o final da adolescência, que estão passando por modelagens na sua personalidade, definições de conceitos e comportamentos, que podem ser determinantes para um bom desenvolvimento psicológico, como no caso do autoconceito, importante durante diversas situações da vida, como o ambiente escolar (Serassuelo et al., 2012; Klapp, 2017).

Este construto pode ser considerado o fator pelo qual o indivíduo se observa no mundo, ou seja, é a capacidade de se enxergar perante um sujeito que ele projeta como o ideal (Serra, 1988; Serassuelo \& Júnior, 2012; Weimer \& Moreira, 2014). Com base em estudos do autoconceito, é possível verificar relações com outras variáveis fundamentais e impactantes na literatura, como a autoeficácia, e assim constatar a relevância de competências psicológicas no desenvolvimento de um aluno/atleta.

A autoeficácia, gira em torno da melhor tomada de decisão: o indivíduo tende a agir com eficácia e resolver seus problemas sem se omitir deles, além de atua com convicção em suas execuções. E este construto tem sido usado com uma ferramenta para compreender o desenvolvimento dos aspectos psicológicos envolvendo a fase escolar e a fase da construção desde a infância até a fase final de formação da adolescência, indo para a fase adulta (Bandura, 1997, Gomes, 2018; Heinemann et al., 2018). 
O autoconceito e a autoeficácia são fatores psicológicos que podem impactar diretamente na performance de um treinamento, de uma competição ou dentro do contexto social do basquetebol. Exemplos disso seriam as percepções sobre as execuções dos fundamentos técnicos e táticos da modalidade, que, se positivas, projetam uma melhor visão do atleta de si mesmo e uma boa eficácia na execução, o que vem a contribuir para o jogo do atleta e o desenvolvimento de suas competências psicológicas (Alves et al., 2008, Grigoletto et al., 2014, Couto et al., 2019, Alves et al., 2019; Biscaia, 2020).

Outra variável estudada pela ciência, considerada indiscutível no ambiente esportivo e indispensável para o esporte, é a denominada neste estudo tempo de treinamento, que por ser um conceito amplo é planejada e pode ser compreendida do microciclo ao macrociclo, respeitando diversos fatores como a maturação, precocidade, idade cronológica atribuída a uma periodização que pode ser compreendida pelo tempo de treino (Grigoletto et al., 2014, 2014; Bompa et. al., 2019, Alves et al., 2019).

O tempo de treinamento relacionado a condições psicológicas dentro das dimensões do autoconceito e autoeficácia mostra-se importante em outros estudos, pois o aluno de basquetebol ou de outras modalidades vem compreendendo as diferentes formas de enxergar-se perante o outro e o quanto é possível existir relações das variáveis mencionadas com o lado emocional, psicológico, físico e acadêmico (Reverdito, 2016, Couto et al., 2019; Alves et al., 2019; Biscaia, 2020; Rocha, 2020).

Um exemplo das dimensões relacionadas ao tempo de treinamento associados à percepção do autoconceito e da autoeficácia é o estresse emocional, pois caso o mentor não siga um planejamento organizado, respeitando o tempo de treino, as cargas do condicionamento físico, técnico e tático, é possível causar dentro das dimensões do autoconceito e da autoeficácia uma percepção capaz de provocar sofrimento emocional, psicológico e físico, reversível ou irreversível, chamado de exaustão física ou emocional, já mapeado por alguns estudos (Heinemann et al., 2018, Rocha, 2020, Biscaia, 2020).

Porém, quando um planejamento é executado dentro da modalidade, permite-se buscar uma evolução contínua do atleta, para que se aproxime de um condicionamento ideal, o rendimento esperado pelos técnicos e pelos próprios atletas, e por meio deste ambiente esportivo também se pode estabelecer novas amizades, sentir-se pertencente a um grupo social, e para isso é preciso recorrer a outras ciências que estudam o esporte, como a Pedagogia do Esporte (Oliveira et al., 2012; Maciel, 2017; Santos Branquinho et al., 2019; Oliveira et al., 2020).

Por meio das vivências diárias do ambiente esportivo, uma relação entre os benefícios e os riscos que o esporte pode trazer, há um outro aspecto relevante para que o atleta se conheça e tenha percepções sobre si mesmo e sobre o ambiente em que está inserido. Define-se este termo como a Qualidade de Vida, conceito multidimensional que integra fatores sociais, ambientais, físicos, psicológicos, e que até pode ser influenciado pela espiritualidade (Whoqol, 1995; Barros et al., 2008; OMS, 2010).

A percepção do atleta sobre sua qualidade de vida é importante para o seu desenvolvimento de modo geral, principalmente em relação às composições dos processos cognitivos, as quais recebem influências do dia a dia dos atletas, pois conectam-se com a consciência e o conhecimento, entre eles a percepção e o pensamento, ou seja, segundo os autores o pensar é algo contínuo, durável e fundamental para o indivíduo, de seu desenvolvimento inicial como criança ao desenvolvimento final da vida (Vagetti et al., 2013).

Quando buscamos na literatura estudos que abordam a qualidade de vida com o esporte, evidencia-se que a prática esportiva possibilita ao seu praticante uma maior percepção dos fatores que interferem nos domínios da sua qualidade de vida, sejam eles aspectos físicos, sociais, intrapessoais e até mesmo o rendimento esportivo (Alves et al., 2018; Heinemann et al., 2018; Santos, 2018).

No caso do basquetebol, há um impacto na qualidade de vida dos alunos de forma positiva, permitindo o bem-estar, a boa satisfação de compartilhar o ambiente do basquete, de fazer amizades, de criar valores como o trabalho em equipe e de ter 
motivação na prática, como demonstram os estudos de (Dante, 2009; Oliveira \& Paes, 2012, Secco et al., 2017); Oliveira et al., 2020).

Já (Abruzzo et al., 2016) demonstraram a importância da participação dos estudantes em atividades extracurriculares oferecidas pela escola, sendo um ambiente de melhora do desempenho escolar. Os treinamentos de basquetebol também geram estresse negativo e estudos sugerem que podem afetar mais o sexo feminino, ou que atletas com pouca experiência tendem a sentir mais a pressão dos treinos e os jogos podem até gerar um tipo de sofrimento pré-jogo ou pré-treino, sendo possível impactar em suas percepções, principalmente a da autoeficácia (Ulz, 2020; Biscaia, 2020). Em outros estudos com jovens atletas de basquetebol que relacionaram fatores psicológicos como a motivação na prática, elucidou-se não ter relações efetivas com as dimensões do estresse, saúde, competitividade, saúde, estética que o basquetebol pode ajudar o atleta a ter mais percepções positivas comparado aos que não jogam (Saldanha et al., 2018).

Por meio dos aspectos positivos e negativos dentro do esporte deve-se buscar entender as relações existentes entre as competências psicológicas, o ambiente, o desempenho esportivo e o desenvolvimento do atleta, para que possamos compreender a influência de cada variável dentro do contexto e de uma em relação a outra (Heinemann et al., 2018; Biscaia, 2020; Rocha, 2020).

O estudo trouxe dados que evidenciam jovens atletas de basquetebol de 12 a 17 anos, de ambos os sexos, que participaram dos Jogos Escolares de 2019, Fase Regional - Curitiba, com amplitude nos ambientes formais, não formais e informais (Szeremeta, 2018).

Questiona-se então: o basquetebol praticado em clubes, escolas e centros municipais de esportes de prefeituras são ambientes que por meio dos treinamentos e competições possibilitam o desenvolvimento do autoconceito, da autoeficácia e da percepção da qualidade de vida dos seus praticantes?

Diante do exposto, o presente estudo teve como objetivo verificar a relação do tempo de treinamento e da autoeficácia com o autoconceito e a qualidade de vida em jovens alunos/atletas de Basquetebol da cidade de Curitiba, Paraná e região metropolitana.

\section{Metodologia}

Trata-se de um estudo quantitativo de cunho transversal com delineamento descritivo de correlação, com participantes selecionados aleatoriamente. Thomas \& Nelson (2012). Para fins de transparência do documento, foi anexada na plataforma Open Science Framework (OSF) e está aberta aos demais pesquisadores que tenham intenção em obter mais conhecimento sobre o tema que foi pesquisado e como foi sua construção primária (Rocha et al., 2022).

\subsection{Participantes}

A população do estudo compreende os atletas participantes dos jogos escolares da fase regional de Curitiba, totalizando 197 alunos/atletas de basquetebol, feminino e masculino, participantes dos jogos escolares do estado do Paraná no ano de 2019, nas categorias A (15 a 17 anos) e B (12 a 14 anos) da cidade de Curitiba, Paraná- Brasil. Participaram da pesquisa alunos oriundos de escolas públicas e particulares e de clubes esportivos envolvidos na modalidade.

\subsection{Instrumentos}

Os instrumentos utilizados na pesquisa foram:

- Sociodemográfico: Desenvolvido pelos autores, contendo perguntas simples para a caracterização da amostra, como sexo, idade, escolaridade, categoria esportiva e tempo de prática semanal.

- Critério Brasil de Classificação Econômica - ABEP (2018): utilizado para caracterizar o nível econômico da 
amostra, este instrumento aponta os níveis sociais dos participantes, que podem ser classificados em rankings sociais, sendo: Classe A - R\$23.345,11; Classe B1 - R \$10.386,52; Classe B2 - R\$5.363,19; Classe C1 - R\$2.965,69; Classe C2 - R\$1.691,44 e Classe D-E - R $\$ 708,19$.

- Escala de Autoeficácia Geral Percebida - EAGP: constitui uma escala de autorrelato com 10 itens em formato Likert, em que as opções de resposta variaram entre $1=$ Muito baixas e $5=$ Muito altas. O questionário foi validado para a realidade brasileira por (Sbicigo et al., 2012).

- Escala Multidimensional de Autoconceito - AF5: desenvolvida por (Garcia \& Musitu 1999), ela foi traduzida para a língua portuguesa por (Coelho et al., 2015) e apresenta os domínios acadêmico, social, familiar, físico e emocional. Essa escala é ideal para medir o Autoconceito em alunos com idades compreendidas entre 10 e 62 anos. Consta de 30 questões formulados em termos positivos e negativos, em uma escala de Likert com um nível de resposta que oscila de 1 a 99 , sendo "1" a pontuação que designa total desacordo com a formulação do item e "99" um total acordo com ele. A maior pontuação em cada um dos fatores mencionados corresponde a um maior autoconceito em determinado domínio, portanto, o autoconceito de cada domínio pode varia de 0 a 100.

- Questionário para qualidade de vida em crianças e adolescentes -KIDSCREEN-52: validado no Brasil por (Guedes et al., 2011), este instrumento abarca 52 questões de múltipla escolha distribuídas nas dimensões: saúde e atividade física (AFS), sentimentos, estado emocional, autopercepção, autonomia, ambiente familiar, aspecto financeiro, amigos e suporte social, ambiente escolar e bullying. O questionário possibilita a avaliação do bem-estar e da saúde subjetiva de crianças e adolescentes. As respostas de cada item do questionário se configuram em escala Likert, variando de um a cinco pontos, e estão relacionadas a acontecimentos ocorridos na semana anterior à aplicação do questionário.

\subsection{Procedimentos}

Os dados foram coletados de agosto a novembro de 2019. A coleta foi realizada em dois momentos. No primeiro momento foi realizado um encontro para apresentar os objetivos do estudo e entregar os Termos de consentimento livre e esclarecido e assentimento livre esclarecido aos participantes. Em um segundo encontro, foi realizada a coleta de dados com os participantes que aceitaram participar da pesquisa, com os termos assinados. A resolução dos questionários da pesquisa foi realizada em uma sala reservada pela própria equipe de pesquisadores, para que os participantes tivessem um maior conforto para realizar a pesquisa. Foram considerados fatores de exclusão praticar outro esporte, a não entrega dos termos de consentimento e assentimento e atletas que não pertenciam à faixa etária estipulada na pesquisa.

\subsection{Análise dos Dados}

Os dados foram tabulados e analisados via pacote estatístico SPSS 24.0. Foram realizadas análises descritivas (média, máximo, mínimo, desvio padrão, frequência, porcentagem e porcentagem acumulada) das variáveis do estudo. Na análise inferencial, foi realizada a regressão linear múltipla, tendo como variáveis dependentes o autoconceito e a qualidade de vida (e suas facetas) e como variáveis independentes a frequência de treinamento e a autoeficácia. O teste utilizado atendeu a todos os pré-requisitos necessários para análise. Foram controladas as variáveis: nível econômico, sexo e idade. A significância adotada foi de $\mathrm{p} \leq 0,05$.

\subsection{Aspectos Éticos}

Este estudo foi submetido ao Comitê de Ética em pesquisa, da Universidade Federal do Paraná, seguindo todas as recomendações da Resolução n. ${ }^{\text {o }}$ 466/ 2012 do CNS e aprovado pelo parecer 3275069. 


\section{Resultados e Discussão}

$\mathrm{Na}$ análise descritiva, observa-se que os atletas praticantes de basquetebol, em sua maioria, são de classe econômica A (58\%), estudam no ensino fundamental $(60,91 \%)$, estão na categoria esportiva B $(55,8 \%)$, são do sexo masculino (79,7\%) e treinam 4 vezes por semana $(37,1 \%)$. Demais informações encontram-se na Tabela 1.

Tabela 1- Análise descritiva das variáveis caracterizadoras da amostra de atletas de Basquetebol de Curitiba e região metropolitana, Paraná-Brasil.

\begin{tabular}{|c|c|c|c|}
\hline Variável & $\mathrm{N}$ & $\%$ & $\% \mathrm{~A}$ \\
\hline \multicolumn{4}{|c|}{ Nível socioeconômico } \\
\hline A & 116 & 58,9 & 58,9 \\
\hline B1 & 42 & 21,3 & 80,2 \\
\hline B2 & 26 & 13,2 & 93,4 \\
\hline $\mathrm{C} 1$ & 12 & 6,1 & 99,5 \\
\hline $\mathrm{C} 2$ & 1 & 0,5 & 100,0 \\
\hline Total & 197 & 100,0 & - \\
\hline \multicolumn{4}{|l|}{ Nível Escolar } \\
\hline Médio & 77 & 39,09 & 39,09 \\
\hline Fundamental & 120 & 60,91 & 100,0 \\
\hline Total & 197 & 100,0 & - \\
\hline \multicolumn{4}{|c|}{ Categoria esportiva } \\
\hline $\mathrm{A}$ & 87 & 44,2 & 44,2 \\
\hline B & 110 & 55,8 & 100,0 \\
\hline Total & 197 & 100,0 & - \\
\hline \multicolumn{4}{|l|}{ Sexo } \\
\hline Feminino & 40 & 20,3 & 20,3 \\
\hline Masculino & 157 & 79,7 & 100,0 \\
\hline Total & 197 & 100,0 & - \\
\hline \multicolumn{4}{|c|}{ Frequência de Treinamento (em dias) } \\
\hline 1 & 1 & 0,5 & 0,5 \\
\hline 2 & 62 & 31,5 & 32,0 \\
\hline 3 & 40 & 20,3 & 52,3 \\
\hline 4 & 73 & 37,1 & 89,3 \\
\hline 5 & 13 & 6,6 & 95,9 \\
\hline 6 & 8 & 4,1 & 100,0 \\
\hline Total & 197 & 110,0 & - \\
\hline
\end{tabular}

Fonte: Rocha et al., (2022). 
A média de idade dos atletas é de 14,24 anos (dp¹,65). Em relação ao treinamento semanal, a média é de 3,30 dias na semana $(\mathrm{dp} \pm 1,12)$. Na variável autoconceito, o melhor escore é do Autoconceito Físico $(\mathrm{M}=77,18 ; \mathrm{dp} \pm 14,13)$ e o menor, no Autoconceito emocional $(M=43,30 ; \mathrm{dp} \pm 18,25)$. A autoeficácia pode ser considerada alta, visto a média de 31,55 (dp $\pm 4,17)$. Na análise descritiva da qualidade de vida, pode-se observar o melhor escore no domínio Sentimentos $(M=81,25 ; \mathrm{dp} \pm 15,32)$, tendo o menor escore no domínio Provocação/Bullying $(M=13,57$; dp $\pm 17,45)$. Demais informações sobre a caracterização da amostra encontram-se na Tabela 2.

Tabela 2- Análise descritiva com média, mínimo, máximo e desvio padrão das várias idades, dias de treinamento semanal, autoconceito, qualidade de vida de adolescentes e autoeficácia da amostra de atletas de Basquetebol de Curitiba e região metropolitana, Paraná-Brasil.

\begin{tabular}{|c|c|c|c|c|}
\hline Variáveis & Média & Mínimo & Máximo & DP \\
\hline Idade & 14,24 & 11 & 17 & 1,65 \\
\hline Treinamento $*$ & 3,30 & 1 & 6 & 1,12 \\
\hline A. Acadêmico & 76,56 & 9,66 & 99,00 & 14,50 \\
\hline A. Social & 66,24 & 14,83 & 97,16 & 11,31 \\
\hline A. Emocional & 43,30 & 3,83 & 43,30 & 18,25 \\
\hline A. Familiar & 64,16 & 21,83 & 99,00 & 15,48 \\
\hline A. Físico & 77,18 & 12,33 & 99,00 & 14,13 \\
\hline Autoeficácia & 31,55 & 17 & 40 & 4,17 \\
\hline AFS & 80,32 & 35 & 100 & 14,66 \\
\hline Sentimentos & 81,85 & 20,83 & 100 & 15,32 \\
\hline Emocional & 27,75 & 0,00 & 89,28 & 18,30 \\
\hline Autopercepção & 64,02 & 25,00 & 100,00 & 12,72 \\
\hline Autonomia & 75,00 & 15,00 & 100,00 & 18,30 \\
\hline Família & 77,87 & 1,16 & 100,0 & 20,07 \\
\hline Financeiro & 70,30 & 0,00 & 100,0 & 24,13 \\
\hline Amigos & 80,71 & 12,50 & 100,0 & 15,81 \\
\hline Escolar & 68,50 & 8,33 & 100,0 & 17,51 \\
\hline Provocação & 13,57 & 0,00 & 100,0 & 17,45 \\
\hline Geral & 62,97 & 36,44 & 79,03 & 7,38 \\
\hline
\end{tabular}

Fonte: Rocha et al., (2022).

$\mathrm{Na}$ análise inferencial, quando controladas as variáveis nível econômico, sexo e idade, a regressão múltipla mostrou que o tempo de treinamento e a autoeficácia apresentam correlação moderada com o autoconceito acadêmico ( $\mathrm{R}=0,350$; $\mathrm{p} \leq 0,000)$ e físico $(\mathrm{R}=0,376 ; \mathrm{p} \leq 0,000)$, explicando de 12 até $14 \%$ da boa percepção do autoconceito (respectivamente). Em relação à qualidade de vida, a frequência de treinamento e autoeficácia apresentaram correlações moderadas nos domínios Saúde e Atividade Física $(R=0,484 ; p \leq 0,000)$, Sentimentos $(R=0,484 ; p \leq 0,000)$, Emocional $(R=0,349 ; p \leq 0,000)$, Autonomia $(R=0,277 ; p \leq 0,004)$, Financeiro $(R=0,369 ; p \leq 0,000)$, Amigos $(R=0,266 ; p \leq 0,007)$, Escolar $(R=0,464 ; p \leq 0,000)$ e na qualidade de vida geral $(\mathrm{R}=0,382 ; \mathrm{p} \leq 0,000)$. Portanto, a frequência de treinamento e a autoeficácia explicaram de 5 a $23 \%$ da qualidade de vida dos atletas. Demais informações encontram-se na Tabela 3 abaixo. 
Tabela 3- Relação da frequência de treinamento e autoeficácia com o autoconceito e a qualidade de vida da amostra de atletas/alunos de Basquetebol de Curitiba e região metropolitana, Paraná-Brasil.

\begin{tabular}{llll}
\hline Variáveis & \multicolumn{3}{l}{ Tempo de Treinamento e Autoeficácia } \\
\hline & $\mathrm{R}$ & $\mathrm{R}^{2}$ & $\mathrm{P}$ \\
\hline A. Acadêmico & 0,350 & 0,12 & 0,000 \\
A. Social & 0,165 & 0,02 & 0,258 \\
A. Emocional & 0,211 & 0,04 & 0,066 \\
A. Familiar & 0,166 & 0,02 & 0,247 \\
A. Físico & 0,376 & 0,14 & 0,000 \\
AFS & 0,484 & 0,23 & 0,000 \\
Sent & 0,426 & 0,18 & 0,000 \\
Emocional & 0,349 & 0,12 & 0,000 \\
Autopercepção & 0,121 & 0,01 & 0,587 \\
Autonomia & 0,277 & 0,05 & 0,004 \\
Família & 0,211 & 0,04 & 0,067 \\
Financeiro & 0,369 & 0,13 & 0,000 \\
Amigos & 0,266 & 0,07 & 0,007 \\
Escolar & 0,464 & 0,21 & 0,000 \\
Provocação & 0,212 & 0,04 & 0,065 \\
QV geral & 0,382 & 0,14 & 0,000 \\
\hline
\end{tabular}

Fonte: Rocha et al., (2022).

O presente estudo obteve dados validados de 197 jovens praticantes de basquetebol do sexo feminino e masculino com idade média de 14,24 anos $(\mathrm{dp} \pm 1,65)$. Este estudo mostra que a maioria dos atletas é proveniente de classe alta, descrevendo que em sua maior parte os indivíduos pesquisados têm boas condições de moradia e recursos financeiros.

As condições financeiras podem contribuir para o desenvolvimento esportivo e educacional do praticante. Uma melhor condição financeira permite ter bons estudos e recursos para uma boa manutenção, seja alimentar, seja de estrutura de treino (tênis específico de basquete, bolas, tabela/aro), além de aulas particulares de basquetebol com um profissional da área, afetando assim positivamente o desenvolvimento. Já praticantes com menor condição financeira teriam uma desvantagem na parte estrutural do processo, o que gera obstáculos no desenvolvimento esportivo e educacional (Heinemann e Guterres et al., 2018, Rocha, 2020).

Os dados deste estudo evidenciaram que $37,1 \%$ dos atletas treinam $4 \mathrm{x}$ na semana e que $68 \%$ treinam $\geq 3 \mathrm{x}$ na semana, e essa frequência de tempo de treino pode gerar uma significante diferença, pois pode-se transformar os dias em horas de treino e assim pode-se sofrer alterações nos níveis de desenvolvimento e competição baseando-se no tempo em que se treina (Bompa et. al., 2019; Grigoletto et al., 2014; Alves et al., 2019).

Exemplo disso é que, para se jogar a nível escolar o tempo de treino é menor quando comparado aos níveis municipal, estadual e nacional, encaixando-se nesse quesito a relação treino x nível da competição. Além disso, existe uma relação do tempo de treino com o desenvolvimento de variáveis físicas, psicológicas e sociais, onde um maior tempo de treinamento permite ao praticante estabelecer níveis mais satisfatórios destas variáveis (Grigoletto et al., 2014; Oliveira, 2017; Bompa et al., 2019; Oliveira, Paes et al., 2020). 
Para o Autoconceito, os níveis estabelecidos pelos atletas são considerados satisfatórios para dimensões do autoconceito acadêmico, social, familiar e físico. Somente a dimensão emocional estabeleceu um índice não tão satisfatório, o qual pode ter relação com a visão que se tem do treino, com a derrota de um jogo, com uma lesão, ou até mesmo com o início ou término de um relacionamento de amizade ou de namoro, o que pode ocasionar uma espécie de sofrimento emocional. Isso ocorre porque é um período em que há diversas transições sociais, físicas, financeiras, da autonomia e liberdade de adolescente que impactam nas condições emocionais. A emoção é algo difícil de ser controlado e necessita de experiências de vida, nesse caso o esporte pode ser um gerador de estresse físico e emocional (Galatti, 2006; Damásio, 2013).

A Autoeficácia teve seu escore considerado alto, elucidando as possíveis boas ações na execução da tarefa, sejam elas em jogos ou em fundamentos do jogo. É possível que o aprender dos gestos técnicos do basquete com eficácia seja um fator que melhore esta percepção, que é definida como o indivíduo que compreende e reage diante de diferentes situações usando sua competência para tomar decisões e agir com a melhor eficácia possível procurando resolver problemas sem omitir-se deles e tendo persuasão na execução das tarefas (Piccoli et al., 2014; Reverdito, 2016).

Na tabela três, na relação tempo de treinamento e autoeficácia com o autoconceito pode-se verificar uma relação direta com o autoconceito acadêmico e o físico. Na dimensão do acadêmico fica perceptível que o aluno que está inserido no basquetebol, com mais tempo de treinamento e uma adequada percepção em cima de sua autoficácia, consegue estabelecer uma melhor percepção dos seus rendimentos escolares, ou seja, se maior seus níveis de treinamento e autoeficácia, maior será sua percepção sobre seus rendimentos acadêmicos. O jovem praticante de basquetebol que tem bons resultados na escola pode ter impactos nestes aspectos psicológicos e é possível que haja influências positivas para a sua qualidade de vida geral (Albuquerque et al., 2002; Rocha, 2020).

Na dimensão do autoconceito físico também se constatou uma relação de melhora, visto que o jogo de basquetebol faz o uso contínuo da parte física do praticante, possibilitando ao aluno/atleta a compreensão da percepção que ele tem de seu próprio físico, como se enxerga e o quanto a prática do basquetebol tem interferido positivamente devido aos treinos físicos, além de possibilitar o não sedentarismo, contribuindo também com a melhora das condições motoras, indo na mesma linha de raciocínio que os autores (Azevedo et al., 2007; Serassuelo et al., 2012).

O basquete é um jogo coletivo intenso fisicamente e os atletas que compreendem seus propósitos e os objetivos esquematizados pelos professores/técnicos apresentam o ganho de melhores condições físicas e uma percepção mais aguçada de sua condição física, pois o jogo irá exigir o melhor de seu condicionamento físico, que é adquirido com o treinamento (Oliveira et al., 2020).

Após a análise inferencial de correlação do tempo de treinamento e a autoeficácia com a qualidade de vida, notou-se resultados positivos relacionados aos atletas pesquisados, sendo que essas inferências estão relacionadas às dimensões da saúde e atividade física (AFS), sentimentos, estado emocional, autonomia, financeiro amigos e ambiente escolar (Guedes \& Guedes, 2011).

Dentro da dimensão física (AFS) pode-se seguir a mesma linha de estudos que comprovam que se praticando uma atividade esportiva com frequência e tempo de treinamento com carga suficiente para que exista ganhos poderá haver melhores regulações nos sistemas parassimpáticos, que causam interações em outros sistemas do corpo humano, um deles o hormonal (Oliveira et al., 2007; Alves et al., 2019).

No aspecto psicológico (sentimentos, estado emocional) o basquetebol permite ao seu praticante diversas experiências e por meio delas é que ocorre um maior controle do praticante sobre si mesmo, sendo isso construído desde uma simples roda de bate papo antes de um treinamento até uma final de campeonato brasileiro. Esse desenvolvimento psicológico não se deve somente a situações positivas, de títulos, mas a derrota tem seu papel de formação esportiva, social e educacional, estimulando o aluno/atleta a saber lidar com a adversidade (Dante, 2009; Gomes, 2018). 
Além disso, o apoio emocional, principalmente da relação do meio extrínseco para o intrínseco tem grande contribuição para o desenvolvimento psicológico do atleta dentro do esporte. O estudo de (Folle, 2016) vem contribuir com os achados deste estudo, pois define, dentro dos aspectos psicológicos relacionados ao basquetebol, que quando se segue uma linha de desenvolvimento e respeita-se as diferentes fases de maturação, permite-se ao seu praticante que consiga ter resultados positivos na construção de atleta e pessoa.

Um fato que chamou a atenção dentro do estudo é que mesmo a dimensão do estado emocional apresentando uma média baixa existe uma relação positiva dentro da regressão e assim percebe-se a importância do basquete na contribuição para uma melhora deste índice, sendo um esporte de construção individual e social, principalmente quando relacionado ao conflito biológico e emocional característico da idade (Oliveira et al., 2012; Gomes, 2018; Rocha, 2020).

Para o domínio de independência (autonomia e financeira), no âmbito da autonomia o estudo corrobora os estudos de (Rocha, 2020) e (Biscaia, 2020), que evidenciaram que os praticantes de basquetebol e futsal das idades de 12 a 17 anos, de ambos os sexos, sabem se organizar, tomam ações independentes, sabem como treinar, sabem se ocupar nos momentos vagos e sabem qual caminho será percorrido com vontade própria, e esta capacidade de decisão é atrelada às construções dentro do próprio esporte.

A dimensão financeira expõe que melhores condições de estruturação do esporte possibilitam um melhor desenvolvimento do seu praticante, ou seja, quanto maiores os recursos, maiores podem ser as oportunidades que impactam no processo de aprendizagem, seja o de treinos ou o de estudar. Isso se deve ao fato de que ser um aluno/atleta demanda de uma boa alimentação que geralmente tem o custo elevado, uma cautela com relação à saúde, entre diversos fatores que possam contribuir para o bom desenvolvimento e rendimento esportivo ou educacional (Heinemann et al., 2018).

Dentro do aspecto social destacam-se significativamente os resultados da dimensão amigos e escola e por meio disso é possível verificar o basquete como um ambiente que permite auxiliar na construção destas dimensões, pois o esporte é um ambiente socioeducacional. O ambiente do basquetebol é rico para conseguir fazer novas amizades, isso pode ser percebido por meio da afetividade observada dentro e fora das quadras, transcendendo até o próprio jogo (Secco \& Oliveira, 2017; Rocha, 2020).

Segundo (Folle, 2016) que expõe que o apoio social é de fundamental importância para a sequência do atleta dentro do esporte, sendo assim a construção social e esportiva mostra a relevância de estar com pessoas que te apoiam e auxiliam para passar pelos obstáculos.

Para a dimensão do ambiente escolar ficou evidenciado que o esporte é um ambiente socioeducacional, pois as relações positivas encontradas vão ao encontro da literatura, que avaliou em um ambiente escolar a qualidade de vida dos alunos numa amostra de 63 adolescente de 14 anos, utilizando, como instrumento, o Kidscreen-52. Os resultados sugeriram que eles possuem boa percepção da Qualidade de Vida, pois os escores foram superiores a 60,0 (Mendes et al., 2014). E com o de (Rocha, 2020), em que os não praticantes ficaram com escores inferiores aos praticantes de basquetebol, podendo-se dizer que praticar basquetebol pode melhorar essa percepção.

Quando analisada a qualidade de vida geral, segundo os autores, o treinamento como prática de atividade física corrobora o não sedentarismo, possibilitando um nível satisfatório de atividade física, colaborando com a qualidade de vida geral dos praticantes de basquetebol e indo junto aos estudos da literatura que relatam a importância do equilíbrio hormonal, o fortalecimento da construção óssea, o fortalecimento psicológico e a construção de elos sociais que trazem um suporte no desenvolvimento global do aluno/atleta (Tani, 2002; Cunha, 2008; Alves \& Lima, 2008; Heinemann e Guterres et al., 2018; Biscaia, 2020).

A atual pesquisa tem uma limitação que está relacionada ao uso de um delineamento transversal para indicar associações entre as variáveis. Sugere-se a realização de um estudo usando outros instrumentos de avaliação mais específicos 
para o basquetebol, que atenda outras variáveis psicológicas que também possam impactar em novos resultados e novas associações.

\section{Conclusão}

Diante dos resultados apresentados, pode-se dizer que o basquetebol desenvolvido em escolas públicas e privadas da cidade de Curitiba, Paraná, Brasil tem influências positivas para os seus praticantes, interferindo de maneira positiva na construção da vida escolar, esportiva e social dos jovens. Vale ressaltar que os níveis estabelecidos nas variáveis do autoconceito, autoeficácia e qualidade de vida foram satisfatórios dentro da perspectiva do basquetebol escolar.

Percebe-se a contribuição da modalidade para aspectos intrínsecos, uma capacidade do jovem aluno/atleta, de desenvolver um olhar crítico e autoperceptivo, para que assim possibilite ver o seu desenvolvimento esportivo, social e educacional e quais aspectos precisam ser melhorados.

Já o autoconceito emocional e a dimensão emocional da qualidade de vida mostraram níveis menores, ligando um alerta sobre este tema, mas quando realizada a análise inferencial de regressão constatou-se que relacionada à autoeficácia e ao tempo de treinamento esta variável emocional sofre uma influência positiva da modalidade, sendo assim, pode-se dizer que o basquetebol é capaz de gerar melhorias para o emocional do aluno/atleta, e cabe ao profissional da área contribuir para este desenvolvimento estando conecto a pedagogia do esporte aliado a educação.

Explanamos como sugestão aos pesquisadores que estudam o tema, que procurem utilizar instrumentos qualitativos com ênfase em instrumentos quantitativos, que possam tratar as variáveis do meio ambiente que estão influenciando não apenas o aluno/atleta de basquetebol, mas em todo ecossistema educacional/esportivo das escolas públicas e privadas.

\section{Agradecimentos}

Agradecemos aos orientadores por todo aprendizado que nos proporcionaram junto a Universidade Federal do Paraná, setor de Educação, linha de Cognição, Aprendizagem e Desenvolvimento Humano em conjunto da equipe de professores.

Financiamento. O presente trabalho foi realizado com apoio da Coordenação de Aperfeiçoamento de Pessoal de Nível Superior (CAPES/ PROEX/ CNP).

\section{Referências}

Abruzzo, K. J. (2016). Does Participation Extracurricular Activities Impact Student. Journal for Leadership and Instruction, 15(1), 21-26. https://files.eric.ed.gov/fulltext/EJ1097547.pdf

Albuquerque, C., \& Oliveira, C. P. F. D. (2002). Características psicológicas associadas à saúde: a importância do auto-conceito. Millenium.. https://repositorio.ipv.pt/handle/10400.19/625

Alves, B. G., \& Alves, V. G. (Abril de 2019). Efeitos da atividade Física sobre o crescimento de crianças. Jornal de Pediatria, 95. doi: 0021-7557.doi: https://doi.org/10.1016/j.jped.2018.11.003

Alves, C., \& Lima, R. V. (2008). Impacto da atividade física e esportes sobre o crescimento e puberdade de crianças e adolescentes. Revista Paulista de Pediatria , 26, 383-391. doi: https://doi.org/10.1590/S0103-05822008000400013

Alves, M. A., Kviatkovski, B. L., \& Blazelis, R. (2018). Avaliação da qualidade de vida em jogadoras de futsal no estado do paraná: por meio do instrumento whoqol-bref. RBFF-Revista Brasileira de Futsal e Futebol, 10, 278-284. http://www.rbff.com.br/index.php/rbff/article/view/588

Bandura, A. (1997). Self-efficacy: the exercise of control. New York: Freeman.doi:10.1891/0889-8391.13.2.158

Barros, S. P., Cobo, V. J., \& Fransozo, A. (2008). Feeding habits of the spider crab Libinia spinosa H. Milne Edwards, 1834 (Decapoda, Brachyura). Brazilian Archives of Biology and Technology, 51(2), 413-417. doi: https://doi.org/10.1590/S1516-89132008000200023

Biscaia, R. R. (março de 2020). Associação do autoconceito, autoeficácia e qualidade de vida entre escolares de 15 e 17 anos praticantes e não praticantes de futsal em Curitiba. doi: 10.37885/201102298 
Bompa, T. e. (2019). Periodização integrada no treinamento esportivo e desenvolvimento atlético: Combinando metodologia de treinamento, psicologia do esporte e nutrição para otimizar o desempenho. Meyer \& Meyer Sport. https://bityli.com/pfjqU

Coelho, V. A., Sousa, V., Marchante, M., \& Romão, A. M. (2015). Validação do questionário Autoconceito Forma 5 numa amostra de crianças e adolescentes portugueses. International Journal of Developmental and Educational Psychology, 1(1), 67-77. https://www.redalyc.org/pdf/3498/349851779008.pdf

Cunha, R. A. (2008). Elaboração e validação do questionário sobre qualidade de vida de atletas (QQVA). https://repositorio.ufmg.br/handle/1843/KMCG7NRM33

Rocha, A. J. P., Gomes, F. R. H., de Oliveira, V., Vagetti, G. C., \& Biscaia, R. R. (2022, January 28). Relação do tempo de treinamento e autoeficácia com o autoconceito e a qualidade de vida em jovens escolares de Basquetebol. https://osf.io/ew49b

Damásio, A. (2013). O homem está evoluindo para conciliar a emoção e a razão. Acesso em 27 de janeiro de 2020, disponível em REVISTA VEJA CIÊNCIA. https://veja.abril.com.br/ciencia/o-homem-esta-evoluindo-para-conciliar-a-emocao-e-a-razao-diz-antonio-damasio/

Dante, D. R. (2009). Esporte e atividade física na infância e na adolescencia (2 $2^{\mathrm{a}}$ ed.). Porto Alegre: Artmed. https://bityli.com/LAZaw

de Azevedo Oliveira, R., de Arruda, M., \& Lopes, M. B. S. (2007). Características do Crescimento e do Desenvolvimento Físico de Pré-Adolescentes e A Relevância do Treinamento de Longo Prazo. Revista de Atenção à Saúde (ISSN 2359-4330), 5(14). http://seer.uscs.edu.br/index.php/revista_ciencias_saude/article/download/393/203

FIBA (10 de Dezembro de 2020). FIBA . Fonte: International Basketball Federation: from http://www.fiba.basketball/

García, F., \& Musitu, G. (1999). Autoconcepto forma 5. Madrid: Tea. https://web.teaediciones.com/ejemplos/AF-5_manual_2014_extracto.pdf

Galatti, L. R. (2006). Pedagogia do esporte: o livro didático como um mediador no processo de ensino e aprendizagem dos jogos esportivos coletivos.doi: https://doi.org/10.5016/1980-6574.2010v16n3p751

Gasparotto, G. d. (2018). Autoconceito de estudantes de ensino médio e sua relação com o desempenho acadêmico: uma revisão sistemática. Revista Portuguesa de Educação, 31, 21-37. from https://www.redalyc.org/jatsRepo/374/37454959006/37454959006.pdf

Gomes, J. H. (2018). Estado de humor e desempenho físico de jogadores jovens de basquetebol ao longo de uma competição. Journal of Physical Education. doi: https://doi.org/10.4025/jphyseduc.v29i1.2969

Guedes, D. P. (2011). Tradução, adaptação transcultural e propriedades psicométricas do KIDSCREEN-52 para a população brasileira. Revista Paulista de Pediatria, 364-371. https://www.scielo.br/j/rpp/a/WqLtcSqtCnsLmCdfkZDwzMM/?format=pdf\&lang=pt

Heinemann, G. E. G., Greguol, M., \& de Oliveira, A. R. (2018). Análise da qualidade de vida em atletas de basquetebol da cidade de Londrina, Paraná Conexões, 16(3), 266-280..doi: https://doi.org/10.20396/conex.v16i3.8649963

Klapp, A. (2017). Does academic and social self-concept and motivation explain the effect of grading on students' achievement? European Journal of Psychology of Education, 33(2), 355-376.doi: https://doi.org/10.1007/s10212-017-0331-3

Lazzoli, J. K., Nóbrega, A. C. L. D., Carvalho, T. D., Oliveira, M. A. B. D., Teixeira, J. A. C., Leitão, M. B., ... \& Matsudo, V. (1998). Atividade física e saúde na infância e adolescência. Revista brasileira de medicina do esporte, 4, 107-109..). https://www.scielo.br/j/rbme/a/FYF9LC6DWWKRDQCz33xwNLk/?lang=pt\&format=pdf

Oliveira, V. D., Paes, R. R., \& Vagetti, G. C. (2020). Basquetebol-Pedagogia, Aprendizagem e Desenvolvimento. Londrina/Paraná: Sport Training, 10, 515523. Londrina/ Paraná: Sport Training. doi: 10.29327/515523

Oliveira, V. D., \& Paes, R. R. (2012). Ciência do Basquetebol: pedagogia e metodologia: da iniciação e especialização (2 ed.). Londrina: Sportraining. https://encurtador.com.br/hDINW

Paes, Roberto Rodrigues. Aprendizagem e competição precoce. O caso do basquetebol, v. 3, 1997. https://encurtador.com.br/cPZ04

Piccoli, J. C., Mendes, D., \& DE Quevedo, D. M. (2014). Qualidade de vida relacionada à saúde de escolares do ensino fundamental. Revista Brasileira de Ciência e Movimento, 47-54. https://encurtador.com.br/ps389

Associação Brasileira de Empresas de Pesquisa. (2016). Critério Brasil 2015 e atualização da distribuição de classes para 2016. Critério de Classificação Econômica Brasil, 1-6. https://www.abep.org/

Reverdito, R. S. (2016). Pedagogia do Esporte e Modelo Bioecológico do Desenvolvimento Humano: indicadores para avaliação de impacto em programa socioesportivo. https://encurtador.com.br/nsDY8

Rocha, A. J. (março de 2020). Associação do autoconceito, autoeficácia e qualidade de vida de jovens praticantes de basquetebol de Curitiba. UFPR, Curitiba. Retrieved from https://oatd.org/oatd/record?record=handlel:18841\%2F67236

Rose Junior, D. D. (2002). A competiçäo como fonte de estresse no esporte. Rev. bras. ciênc. mov, 19-26.. Retrieved from https://pesquisa.bvsalud.org/portal/resource/pt/lil-339470

Saldanha, P. R., Barbosa, L. L., Balbinotti, A. A., \& Florentino, A. A. (2018). Experiência de participação em competições: um estudo sobre a motivação dos jogadores de basquetebol. Revista Brasileira de Psicologia do Esporte, 8. doi: http://dx.doi.org/10.31501/rbpe.v8i1.9322

Santos, L. B. (2018). Percepção do autoconceito físico de escolares de onze a dezesseis anos fisicamente ativos. Lecturas: Educación Física y Deportes, 26, 1625.doi: 10.46642 
Secco, D. \& Oliveira, V. (2017). A afetividade no esporte escolar o caso do Basquetebol (1 ${ }^{\text {a }}$ ed., Vol. 1). (A. e. al, Ed.) Curitiba: APPRIS. Retrieved January 29, 2022 from https://downloads.editoracientifica.org/articles/201102298.pdf

Serassuelo., \& Júnior. (2012). A Percepção do Autoconceito e sua influência no Desempenho Motor em Crianças e Adolescentes. Journal Physical Education, 23. doi: https://doi.org/10.4025/reveducfis.v23i1.11090

Serra, A. S. (1988). O auto-conceito. Análise psicológica. 6, 101-110. January 29, 2022 Retrieved from https://core.ac.uk/download/pdf/70651471.pdf

Silva-Grigoletto, M. E. D., Brito, C. J., \& Heredia, J. R. (2014). Treinamento funcional: funcional para que e para quem?. Revista Brasileira de Cineantropometria \& Desempenho Humano, 16(6), 714-719. doi: https://doi.org/10.5007/1980-0037.2014v16n6p714

Szeremeta, T. P. (2018). Construção e validação de um instrumento de avaliação da trajetória esportiva son a ótica do modelo bioecológico. Retrievied January 29, 2022 from https://www.acervodigital.ufpr.br/handle/1884/59712

Tani, G. (2002). Esporte, educação e qualidade de vida. In: Moreira, WW.; SIMÕES, R. (Orgs). Esporte como fator de qualidade de vida. Piracicaba: UNIMEP. Retrieved January 29, 2022 from https://encurtador.com.br/oqvL2

Thomas, J. R., \& Nelson, J. K. (2012). Métodos de pesquisa em atividade física. (6 ed.). Porto Alegre: Artmed. Retrieved January 29, 2022 from https://encurtador.com.br/botX0

Ulz, M. \&. (2020). A ansiedade como fator de influêcia no desenpenho esportivo de atletas de basquetebol. Revista MotriSaúDe,, 2. Acesso em 30 de janeiro de 2021. Retrieved January 29, 2022 from http://revista.fundacaojau.edu.br:8078/journal/index.php/revista_motrisaude/article/view/221

Vagetti, G. C. (2013). Condições de saúde e variáveis sociodemograficas associadas à qualidade de vida em idosas de um programa de atividade física de Curitiba. Caderno de Saúde Pública, 29(5), 955-969.doi: https://doi.org/10.1590/S0102-311X2013000500013

Weimer, W. R., \& Moreira, E. C. (2014). Violência e bullying: manifestações e consequências nas aulas de Educação Física escolar. Revista Brasileira de ciências do esporte, 36, 257-274. Retrieved January 29, 2022 from https://www.scielo.br/j/rbce/a/XRtMKkHn3gxMbYSvg5rk3pr/?lang=pt\&format=pdf

Whoqol Group. (1995). The World Health Organization quality of life assessment (WHOQOL): position paper from the World Health Organization. Social science \& medicine, 41(10), 1403-1409. doi: https://doi.org/10.1016/0277-9536(95)00112-K 